\title{
Effects of Alprazolam on Driving Ability, Memory Functioning and Psychomotor Performance: A Randomized, Placebo-controlled Study
}

Joris C. Verster, M.S., Edmund R. Volkerts, Ph.D., and Marinus N. Verbaten, Ph.D.

Alprazolam is prescribed for the treatment of anxiety and panic disorder. Most users are presumably involved in daily activities such as driving. However, the effects of alprazolam on driving ability have never been investigated. This study was conducted to determine the effects of alprazolam (1 mg) on driving ability, memory and psychomotor performance. Twenty healthy volunteers participated in a randomized, double-blind, placebocontrolled crossover study. One hour after oral administration, subjects performed a standardized driving test on a primary highway during normal traffic. They were instructed to drive with a constant speed $(90 \mathrm{~km} / \mathrm{h})$ while maintaining a steady lateral position within the right traffic lane. Primary performance measures were the Standard Deviation of Lateral Position (SDLP) and the Standard Deviation of Speed (SDS). After the driving test, subjective driving quality, mental effort, and mental activation during driving were assessed. A laboratory test battery was performed $2.5 \mathrm{~h}$ after treatment administration, comprising the Sternberg Memory Scanning Test, a Continuous Tracking Test, and a Divided Attention Test. Relative to placebo, alprazolam caused serious driving impairment, as expressed by a significantly increased $\operatorname{SDLP}\left(F_{1,19}=97.3\right.$, $\mathrm{p}<.0001)$ and SDS $\left(F_{1,19}=30.4, \mathrm{p}<.0001\right)$. This was confirmed by subjective assessments showing significantly impaired driving quality $\left(F_{1,19}=16.4, \mathrm{p}<.001\right)$, decreased alertness $\left(F_{1,19}=43.4, \mathrm{p}<.0001\right)$, decreased mental activation $\left(F_{1,19}=5.7, \mathrm{p}<.03\right)$ and increased mental effort during driving $\left(F_{1,19}=26.4, \mathrm{p}<.0001\right)$. Furthermore, alprazolam significantly impaired performance on the laboratory tests. In conclusion, alprazolam users must be warned not to drive an automobile or operate potentially dangerous machinery.

[Neuropsychopharmacology 27:260-269, 2002] (C) 2002 American College of Neuropsychopharmacology. Published by Elsevier Science Inc.
KEY WORDS: Alprazolam; Driving; Memory; Psychomotor; Performance

From the Utrecht Institute for Pharmaceutical Sciences, Department of Psychopharmacology, University of Utrecht, The Netherlands.

Address correspondence to: Joris C. Verster, University of Utrecht, Utrecht Institute for Pharmaceutical Sciences, Department of Psychopharmacology, P.O. Box 80082, 3508 TB Utrecht, The Netherlands. Tel.: +31 3025369 09; Fax: +31 3025373 87; E-mail: J.C.Verster@pharm.uu.nl

Received October 1, 2001; revised February 5, 2002; accepted February 11, 2002.

Online publication: 2/14/02 at www.acnp.org/citations/ Npp021402246.
Alprazolam is the most frequently used drug of the benzodiazepine family and is one of the 10 most prescribed drugs in the USA (RxList 2000). Alprazolam, a 1,4-triazolobenzodiazepine analog, has a relatively short half-life, is free from active metabolites and is usually prescribed for the treatment of generalized anxiety and panic disorder. Clinical dosages of alprazolam, administrated in divided doses, range from $0.5 \mathrm{mg}$ to 4 $\mathrm{mg} /$ day for the treatment of anxiety disorder and from 6 to $10 \mathrm{mg} /$ day for the treatment of panic disorder.

Alprazolam has also anticonvulsant and antidepressant properties (Jonas and Cohon 1993; Petty et al. 1995; 
Casacalenda and Boulenger 1998). Since anxiety is often accompanied by depression it is suggested that alprazolam is a more powerful anxiolytic in comparison to other benzodiazepines that lack these antidepressant properties (Petty et al. 1995). The drug has a fast onset to anxiety relief (less than one week) when compared with anxiety treatment with buspirone or SSRIs (two to four weeks).

Besides the benefits of alprazolam's therapeutic effects, commonly reported adverse central nervous system (CNS) effects are sedation, reduced alertness, drowsiness, confusion, sleepiness, dizziness and headache. These adverse effects seem to diminish during treatment; however, they do not disappear completely (O'Sullivan et al. 1994). In addition, long-term alprazolam treatment raised concerns about abuse potential, drug dependency, and withdrawal phenomena.

The effects of alprazolam can be explained by its pharmacological actions in the brain, where it binds with high affinity to the $\mathrm{GABA}_{\mathrm{A}}$ benzodiazepine receptor complex. Alprazolam facilitates the binding of GABA resulting in an increased influx of chloride ions. In turn, the presence of GABA inhibits the action of connected brain structures by interacting with several other neurotransmitter systems, including noradrenergic, serotonergic, cholinergic and opioidergic systems (Julien 1998). The $\mathrm{GABA}_{\mathrm{A}}$ benzodiazepine receptor complex comprises several subunits, of which $\alpha$ and $\gamma$ subunits are able to bind benzodiazepines. Recent evidence (Rudolph et al. 2001; Weinberger 2001) has shown that these subunits can be further divided into numerically labeled isoforms $\left(\alpha_{1}-\alpha_{6}, \gamma_{1}-\gamma_{3}\right)$. It has been shown that activation of $\alpha_{1}$ subunits mediates sedation, anterograde amnesia, and hypnotic effects of benzodiazepines, whereas activation of $\alpha_{2}$ subunits causes antianxiety effects. It is therefore not surprising that $\alpha_{2}$ subunits are abundantly present in the amygdala, hippocampus and cerebral cortex: brain structures that are involved in mediating anxiety processes.

Unfortunately, the effects of alprazolam are not limited to 'therapeutic meaningful' sites of action $\left(\alpha_{2}\right.$ effects), since alprazolam enhances the inhibitory effects of GABA which causes a general slowing of brain activity, resulting in sedation and reduced alertness $\left(\alpha_{1}\right.$ effects).

Taking into account the large number of alprazolam prescriptions, its ambulatory use, and adverse CNS effects, it is evident that the effects of alprazolam on daily activities such as driving a car are of major concern to society. In this context, epidemiological evidence showed increased risk of hip fractures (Ray et al. 1987, 1989) and traffic accidents (Neutel 1995; Hemmelgarn et al. 1997; Barbone et al. 1998) after anxiolytic benzodiazepine use. However, these effects were significant only for benzodiazepines with a long elimination half life $(>24 \mathrm{~h})$, and not for those with a short half life $(<24 \mathrm{~h})$, such as alprazolam (mean half life is approximately $11 \mathrm{~h}$ ). Some epidemiological studies, however, did specifically investigate alprazolam's effects, and an association between alprazolam use and increased risk of falling down has been shown (Mendelson 1996).

The popularity and clinical efficacy of alprazolam has resulted in a large number of studies concerning its effects on various aspects of human performance and memory functioning. These studies consistently reported significant performance impairment after acute dosages (1.0 $\mathrm{mg}$ and higher) of alprazolam in tests measuring skills related to driving, such as tracking (Ellinwood et al. 1985, 1987; Linnoila et al. 1990; Nikaido et al. 1990; Ellinwood et al. 1993; Vermeeren et al. 1995; Kroboth et al. 1998), vigilance performance (Kožená et al. 1995; Suzuki et al. 1995) and reaction speed (Hindmarch 1983; Block and Berchou 1984; Linnoila et al. 1990; Bond et al. 1991; Danjou et al. 1992; Saletu et al. 1994; Kroboth et al. 1998). There is, however, a lively debate concerning the predictive validity of laboratory tests to actual on-the-road driving performance. In this context, it has been shown that laboratory simulation tests are not sensitive when compared with actual on-the-road driving tests during normal traffic (Volkerts et al. 1992).

The effects of alprazolam on driving during normal traffic have not yet been investigated. Referring to the CNS effects of alprazolam and taking its wide use into account, the purpose of the present study was to determine the acute effects of alprazolam $(1 \mathrm{mg})$ on driving ability during normal traffic. In addition, driving-related skills were investigated under controlled laboratory conditions. During driving, motor control is essential to manage safe driving. For example, the driver has to keep the car in a steady position within the traffic lane. To examine motor control, a tracking test was included, comprising an easy and a hard version. Also, continuous demands on working memory are necessary to interact safely with the traffic environment. For example, the driver has to be aware of the approaching vehicles in the adjacent traffic lane in order to take decisions for performing overtaking maneuvers and to respond to road signaling. Therefore, the Sternberg memory scanning test was included in the laboratory test battery. Finally, a divided attention test was included, since the driver has to attend to a number of traffic circumstances during driving that occur simultaneously.

\section{HYPOTHESES}

It is hypothesized that alprazolam will impair driving ability, resulting in significantly increased SDLP and SDS. It is also hypothesized that alprazolam will significantly impair laboratory test performance. 


\section{METHODS}

\section{Subjects}

Twenty healthy volunteers (8 males and 12 females) participated in the study. Mean \pm SD age (overall: $25.1 \pm$ 2.0) was $26.0 \pm 2.5$ years for males and $24.5 \pm 1.3$ years for females. The Medical Ethical Committee of the University Medical Center Utrecht approved the study and subjects were treated according to $\mathrm{ICH}$ guidelines for Good Clinical Practice and the Declaration of Helsinki and its amendments (1996). Each subject was informed beforehand about the possible risks of the driving test and the adverse effects of the treatments involved in the study. Written informed consent was obtained before their inclusion in the study. Subjects were medically screened, used no concomitant medication other than paracetamol and oral contraceptives, and they had no history of alcohol or drug abuse. Before the start and at the end of the study, blood chemistry and hematology and urinalysis were determined. During screening, a 12lead ECG was recorded. These assessments were within normal limits. To confirm compliance, at all visits subjects were tested for the presence of alcohol and drugs of abuse (amphetamines, barbiturates, cannabinoids, benzodiazepines, cocaine and opioids). In addition, female subjects underwent a $\beta$-HCG pregnancy test. None of the subjects were positive on any of these tests. Subjects possessed a driver's license, drove more than $8000 \mathrm{~km} /$ year during the preceding three years, and were trained on all tests to attain baseline values.

\section{Procedure}

In a double-blind crossover design, alprazolam (1 mg) or placebo were administered in identically appearing capsules with $200 \mathrm{ml}$ tap water, exactly $30 \mathrm{~min}$ before a standardized breakfast and $1 \mathrm{~h}$ before the driving test and $2.5 \mathrm{~h}$ before the laboratory test battery. Test days were separated by a washout period of four to 14 days.

\section{The Driving Test}

The standardized 100-km driving tests were performed during normal traffic over a 50-km segment of the primary highway running between two Dutch cities, Utrecht (start and end point) and Arnhem (turning point). The highway consisted of two traffic lanes in both directions. The subjects were instructed to maintain a constant speed $(90 \mathrm{~km} / \mathrm{h})$ and a steady lateral position within the right traffic lane. Lateral position variability (SDLP, $\mathrm{cm})$, i.e. the degree of side-to-side motions of the car within the right traffic lane, and speed variability (SDS, $\mathrm{km} / \mathrm{h}$ ) were the primary measures of the test. In addition, the numbers of excursions out of lane, into the road shoulder or the adjacent traffic lane, were recorded. The meaning of SDLP is illustrated in Figure 1.
For safety reasons, a licensed driving instructor provided with a brake and clutch system accompanied the subject. The driving instructor could correct driving maneuvers of the subjects if warranted. When the driving instructor or the subject felt that it was unsafe to continue, tests were terminated before completion. Data collected during the last completed $10-\mathrm{km}$ segment before stopping was used for each unfinished test.

\section{Subjective Assessments}

After conclusion of the driving test, visual analog scales were completed assessing perceived driving quality, mental effort and mental activation during driving. Before and after the driving test, subjects rated their alertness on a 21-point equal interval scale and reported the occurrence of adverse events.

\section{Laboratory Tests}

All tests were computerized and developed from ERTS (Beringer 1992). Subjects were seated in a soundproof test room, in which the luminosity was kept constant during the study.

\section{Sternberg Memory Scanning Test}

After learning a varied memory set of one to five digits (0-9), a single digit (or probe) was presented. The subject was instructed to indicate by button-press whether the probe was part of the memory-set (presented, right button) or not (not presented, left button). A total of 100 different memory sets were shown. Parameters were reaction time (ms) and the percentage of errors.

\section{Tracking Test}

The subject was instructed to keep an unstable bar in the middle of a horizontal plane by counteracting or reverse its movements with the aid of a computer mouse. If the unstable bar hit the edges of the plane, the subject had to start again. The tracking test comprised an easy and hard version. The parameter for tracking accuracy was the Root Mean Square (RMS) of the deviation of the unstable bar.

\section{Divided Attention Test}

Simultaneously, the easy version of the tracking test and a Sternberg memory scanning test (fixed memory set size of 4 digits) were performed. Subsequently, digits (0-9) were presented on the computer screen and the subject had to indicate by button-press whether the digit was present in the memory set or not. Parameters were the RMS, reaction time (ms) and the percentage of errors. 


\section{CALCULATION AND MEANING OF THE "WEAVING INDEX" (SDLP)}

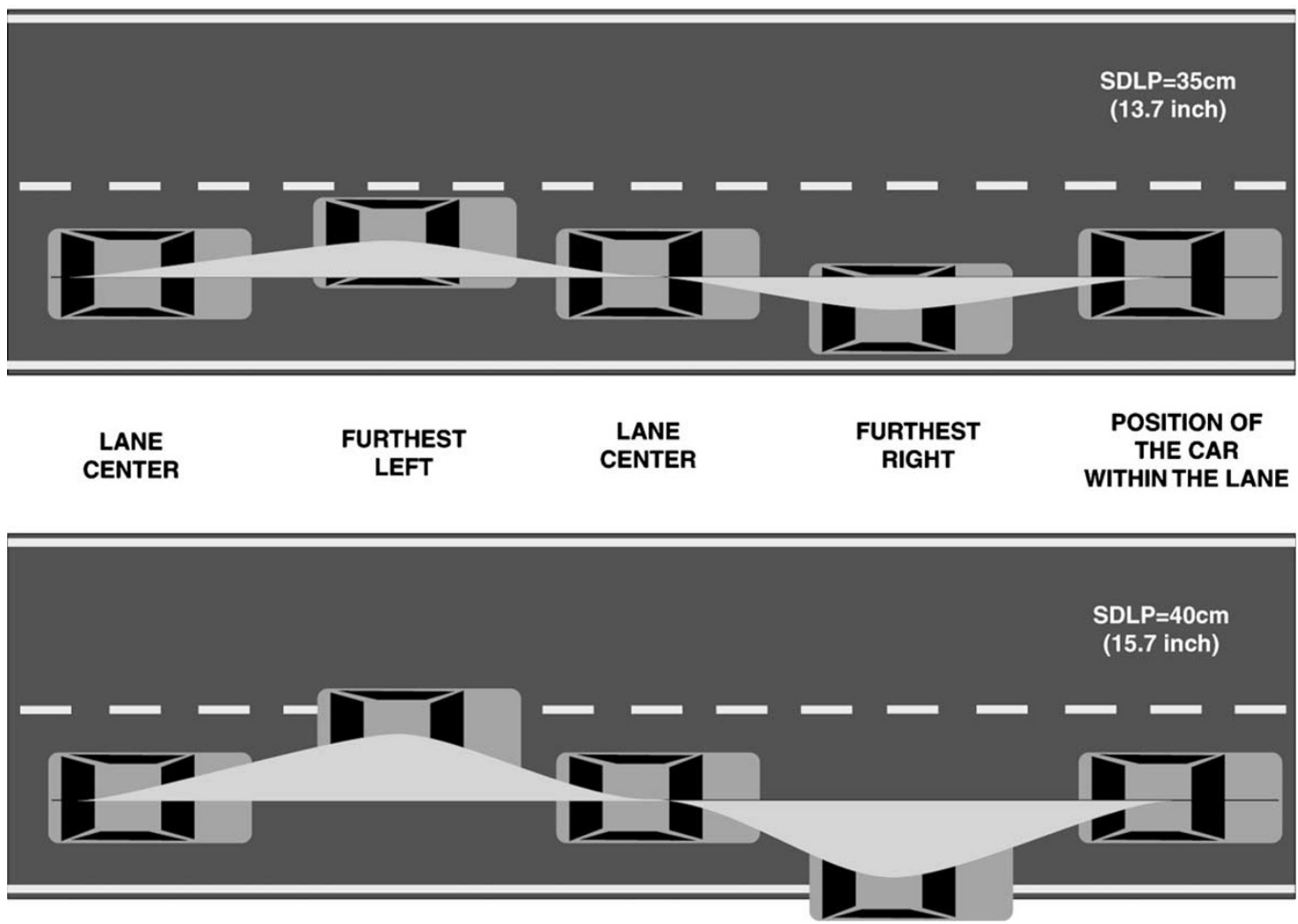

Figure 1. The Standard Deviation of Lateral Position (SDLP).

\section{Statistical Analysis}

Statistical analyses were done employing the SPSS statistical program. For each parameter, mean, standard error $( \pm \mathrm{SE})$ and $95 \%$ confidence interval $(95 \% \mathrm{CI})$ were computed. The factors Treatment and Gender and their interaction were tested for significance (2-sided, $p<$ $.05)$ by using analysis of variance (ANOVA) for repeated measures data. Alternatively, excursions outof-lane were statistically analyzed by using the nonparametric sign test, since these data are not distributed normally. The Sternberg memory scanning test also included the factor Posneg: presented (i.e. part of the memory set) versus not presented (not part of the memory set) and the factor Load (i.e. memory set size, 1 to 5 ). For reaction time data, linear trends as functions of memory set size were computed and slope and intercept were tested for significance. Memory scanning in the divided attention test also included the factor Posneg. Visual analog scales assessing alertness also included the factor Time (before versus after the driving test). Finally, relationships between driving performance (SDLP) and laboratory test performance and subjective assessments were determined employing the Pearson R correlation coefficient.

\section{RESULTS}

The factor Gender and the interaction between Treatment and Gender were not significant for any parameter. Therefore, this factor was excluded from further analyses. Results from the driving test and subjective assessments are summarized in Table 1.

\section{Failure to Complete Tests}

Six subjects were unable to complete their driving test after alprazolam. Their driving tests were terminated prematurely because of seriously unsafe driving, described in Table 2. Their data was included into statistical analyses. All twenty subjects performed the laboratory test battery.

\section{DRIVING TEST}

As evident from Figure 2, driving performance was significantly impaired after alprazolam.

First, ANOVA revealed, relative to placebo, a significantly $\left(\mathrm{F}_{1,19}=97.3, p<.0001\right)$ elevated SDLP after alprazolam. Second, relative to placebo, speed variability was 


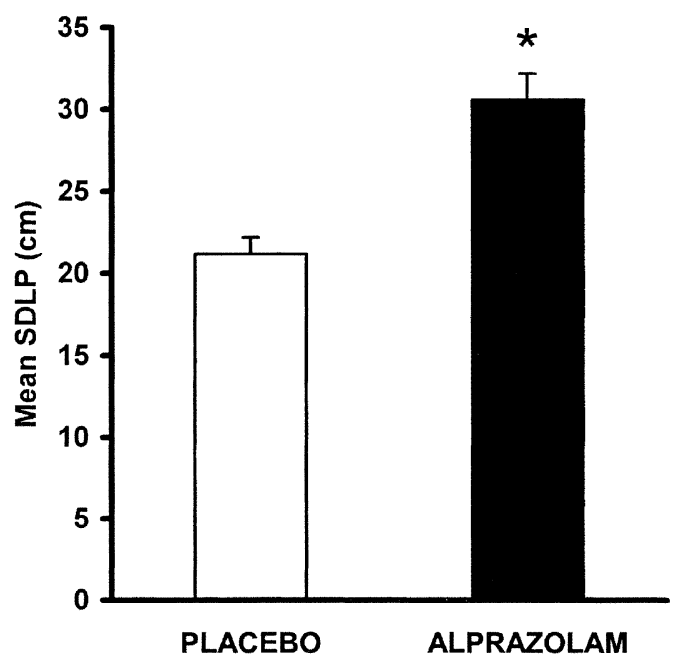

A

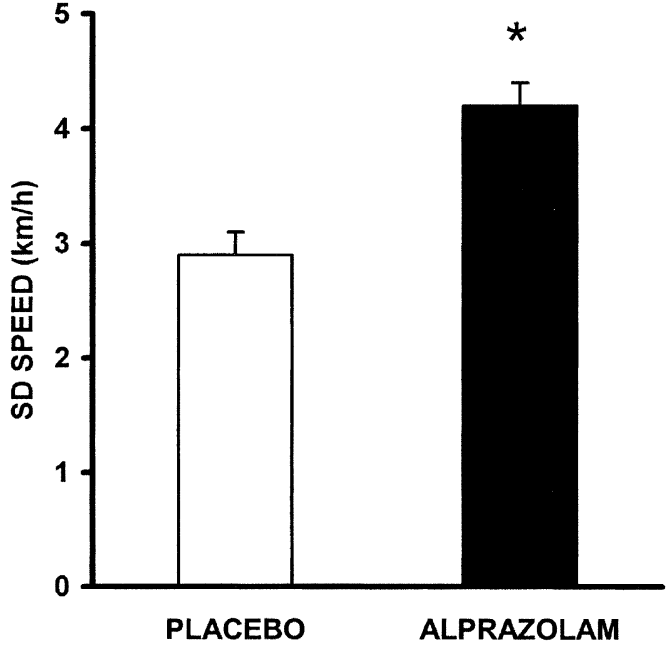

B

Figure 2. Mean (+SE) SDLP and SD speed. Significant $(p<.05)$ differences from placebo are indicated by *

also significantly $\left(\mathrm{F}_{1,19}=30.4, p<.0001\right)$ increased after alprazolam. However, mean speed did not differ between the treatments. Third, excursions out of lane were commonly observed in the alprazolam condition, but generally absent in the placebo condition. Statistical analysis revealed that after alprazolam numbers of excursions out of lane were significantly increased, into both the road shoulder $(p<.02)$ and the adjacent traffic lane $(p<.03)$.

\section{SUBJECTIVE ASSESSMENTS}

Relative to placebo, after alprazolam subjects indicated their subjective driving quality as significantly
$\left(\mathrm{F}_{1,19}=16.4, p<.001\right)$ poorer. Furthermore, subjects confirmed the objective results by reporting significantly $\left(\mathrm{F}_{1,19}=26.4, p<.0001\right)$ increased mental effort and reduced $\left(\mathrm{F}_{1,19}=5.7, p<.03\right)$ mental activation during driving.

Alertness was significantly $\left(\mathrm{F}_{1,19}=43.4, p<.0001\right)$ decreased after alprazolam. In addition, ANOVA revealed a significant $\left(\mathrm{F}_{1,19}=22.2, p<.0001\right)$ overall effect of Time: for both alprazolam and placebo, alertness decreased significantly during the driving test. The interaction between Treatment and Time was not significant. Finally, after alprazolam sleepiness, dizziness and concentration problems were reported more often than after placebo.

Table 1. Summary of the Driving Test Data and Subjective Assessments

\begin{tabular}{|c|c|c|c|c|c|}
\hline \multirow[b]{2}{*}{ Driving test } & \multicolumn{2}{|c|}{ Placebo } & \multicolumn{2}{|c|}{ Alprazolam } & \multirow[b]{2}{*}{ Significance } \\
\hline & Mean \pm SE & {$[95 \% \mathrm{CI}]$} & Mean \pm SE & {$[95 \% \mathrm{CI}]$} & \\
\hline $\operatorname{SDLP}(\mathrm{cm})$ & $21.2 \pm 1.0$ & $(18.9 \leftrightarrow 23.4)$ & $30.6 \pm 1.6$ & $(27.3 \leftrightarrow 33.8)$ & * \\
\hline $\operatorname{MLP}(\mathrm{cm})$ & $8.4 \pm 3.4$ & $(1.3 \leftrightarrow 15.6)$ & $9.5 \pm 4.2$ & $(0.8 \leftrightarrow 18.2)$ & NS \\
\hline $\operatorname{SDS}(\mathrm{km} / \mathrm{h})$ & $2.9 \pm 0.2$ & $(2.4 \leftrightarrow 3.4)$ & $4.1 \pm 0.2$ & $(3.6 \leftrightarrow 4.6)$ & * \\
\hline MS $(\mathrm{km} / \mathrm{h})$ & $89.1 \pm 0.4$ & $(88.2 \leftrightarrow 90.0)$ & $89.4 \pm 0.4$ & $(88.7 \leftrightarrow 90.2)$ & NS \\
\hline Excursions into the adjacent lane & $0.0 \pm 0.0$ & $(0.0 \leftrightarrow 0.0)$ & $1.0 \pm 0.4$ & $(0.1 \leftrightarrow 1.8)$ & * \\
\hline Excursions into the road shoulder & $0.8 \pm 0.3$ & $(0.1 \leftrightarrow 1.5)$ & $6.0 \pm 2.1$ & $(1.7 \leftrightarrow 10.3)$ & * \\
\hline \multicolumn{6}{|l|}{ Subjective assessments } \\
\hline Driving Quality & $10.3 \pm 0.9$ & $(8.4 \leftrightarrow 12.1)$ & $5.1 \pm 0.9$ & $(3.3 \leftrightarrow 7.0)$ & * \\
\hline Mental Effort & $4.3 \pm 0.5$ & $(3.2 \leftrightarrow 5.4)$ & $7.8 \pm 0.7$ & $(6.3 \leftrightarrow 9.2)$ & * \\
\hline Mental Activation & $12.5 \pm 0.7$ & $(11.0 \leftrightarrow 13.9)$ & $9.5 \pm 1.3$ & $(6.7 \leftrightarrow 12.3)$ & * \\
\hline Alertness & $15.3 \pm 0.7$ & $(13.8 \leftrightarrow 16.7)$ & $9.9 \pm 1.2$ & $(7.4 \leftrightarrow 12.4)$ & * \\
\hline
\end{tabular}

Mean $( \pm$ SE) scores and $95 \%$ confidence intervals of the driving test data and subjective assessments. A significant $(P<0.05)$ Treatment effect is indicated by *; NS = not significant, MLP = Mean Lateral Position, MS = Mean Speed. 
Table 2. Failure to Complete Tests.

\begin{tabular}{lllll}
\hline Subject & Gender & Distance & SDLP & \multicolumn{1}{c}{ Reasons for Termination } \\
\hline 1 & male & $50 \mathrm{~km}$ & $31.7 \mathrm{~cm}$ & dizziness, falling asleep \\
2 & female & $30 \mathrm{~km}$ & $37.3 \mathrm{~cm}$ & weakness, falling asleep \\
3 & female & $10 \mathrm{~km}$ & $33.8 \mathrm{~cm}$ & dizziness, weakness, falling asleep \\
4 & female & $40 \mathrm{~km}$ & $29.0 \mathrm{~cm}$ & concentration problems, falling asleep \\
5 & female & $40 \mathrm{~km}$ & $43.1 \mathrm{~cm}$ & concentration problems, dizziness, falling asleep \\
6 & male & $40 \mathrm{~km}$ & $39.1 \mathrm{~cm}$ & dizziness, falling asleep \\
\hline
\end{tabular}

Preliminary terminated driving tests after alprazolam administration. In the placebo condition, all driving tests were completed.

\section{LABORATORY TESTS}

Results from the laboratory tests are summarized in Table 3 and depicted in Figure 3 and Figure 4.

\section{Tracking Test}

ANOVA revealed significant effects of Treatment $\left(\mathrm{F}_{1,19}=\right.$ 35.5, $p<.0001)$, Easyhard $\left(\mathrm{F}_{1,19}=106.4, p<.0001\right)$ and the interaction between Treatment and Easyhard $\left(\mathrm{F}_{1,19}=\right.$ 11.6, $p<.003)$. Relative to placebo, after alprazolam tracking ability was significantly impaired in both the easy condition $\left(\mathrm{F}_{1,19}=31.6, p<.0001\right)$ and hard condition $\left(\mathrm{F}_{1,19}=19.3, p<.0001\right)$ of the tracking test.

\section{Sternberg Memory Scanning Test}

Reaction Time. As evident from Figure 4, reaction time increased with approximately $23 \mathrm{~ms}$ per digit of the memory set. ANOVA revealed significant effects for Treatment $\left(\mathrm{F}_{1,19}=27.1, p<.0001\right)$, Posneg $\left(\mathrm{F}_{1,19}=39.4, p<\right.$ $.0001)$ and Load $\left(\mathrm{F}_{4,16}=8.0, p<.001\right)$. The interaction between Treatment and Posneg also reached significance $\left(\mathrm{F}_{1,19}=4.4, p<.05\right)$. The interaction between Treatment and Load was not significant. ANOVA revealed no significant effects on the percentage of errors data.

Slope and Intercept. ANOVA revealed no significant effects on slope data. In contrast, statistical analysis of intercept data showed a significant $\left(\mathrm{F}_{1,19}=16.4, p<\right.$
.001) Treatment effect. Also, a significant $\left(\mathrm{F}_{1,19}=17.4, p\right.$ $<$.001) Posneg effect was found, reflecting increased reaction time when digits were not part of the memory set. The interaction between Treatment and Posneg was not significant.

\section{Divided Attention Test}

Tracking. Relative to placebo, tracking performance was significantly $\left(\mathrm{F}_{1,19}=32.3, p<.0001\right)$ impaired after alprazolam. Compared with the easy tracking condition, tracking in the divided attention test was significantly $\left(\mathrm{F}_{1,19}=6.5, p<.02\right)$ worse.

Memory Scanning. For reaction time data, ANOVA revealed significant effects of Treatment $\left(\mathrm{F}_{1,19}=19.5, p<\right.$ $.0001)$ and Posneg $\left(\mathrm{F}_{1,19}=27.5, p<.0001\right)$. The interaction between Treatment and Posneg was not significant. In addition, ANOVA revealed a significant $\left(\mathrm{F}_{1,19}=4.7\right.$, $p<.04)$ Treatment effect for percentage of errors, reflecting the significantly increased percentage of errors after alprazolam administration. The effect of Posneg and the interaction between Treatment and Posneg were not significant.

Correlation between SDLP and Laboratory Test Performance. Statistical analysis revealed significant correlations between SDLP and hard tracking $(r=.90, p<$ $.0001)$, tracking in the divided attention test $(\mathrm{r}=.50$, $p<.02)$, and reaction time in the Sternberg memory

Table 3. Summary of Laboratory Test Data

\begin{tabular}{|c|c|c|c|c|c|}
\hline \multirow[b]{2}{*}{ Laboratory tests } & \multicolumn{2}{|c|}{ Placebo } & \multicolumn{2}{|c|}{ Alprazolam } & \multirow[b]{2}{*}{ Significance } \\
\hline & Mean \pm SE & $(95 \% \mathrm{CI})$ & Mean \pm SE & $(95 \% \mathrm{CI})$ & \\
\hline Tracking (easy) & $8.4 \pm 1.7$ & $(4.9 \leftrightarrow 11.9)$ & $17.2 \pm 2.3$ & $(12.5 \leftrightarrow 22.0)$ & $*$ \\
\hline Tracking (hard) & $22.0 \pm 1.5$ & $(18.9 \leftrightarrow 25.1)$ & $26.1 \pm 1.5$ & $(22.9 \leftrightarrow 29.3)$ & * \\
\hline Sternberg memory scanning (RT) & $459.7 \pm 19.2$ & $(419.6 \leftrightarrow 499.8)$ & $559.2 \pm 32.5$ & $(491.2 \leftrightarrow 627.1)$ & * \\
\hline Sternberg memory scanning (errors) & $0.5 \pm 0.1$ & $(0.4 \leftrightarrow 0.7)$ & $0.6 \pm 0.1$ & $(0.4 \leftrightarrow 0.9)$ & NS \\
\hline Divided attention (RT) & $518.2 \pm 17.3$ & $(481.9 \leftrightarrow 554.5)$ & $701.3 \pm 49.5$ & $(597.7 \leftrightarrow 804.9)$ & * \\
\hline Divided attention (errors) & $4.4 \pm 0.6$ & $(3.1 \leftrightarrow 5.8)$ & $8.3 \pm 2.1$ & $(3.8 \leftrightarrow 12.8)$ & * \\
\hline Divided attention (tracking) & $10.1 \pm 1.8$ & $(6.3 \leftrightarrow 13.9)$ & $18.4 \pm 2.3$ & $(13.7 \leftrightarrow 23.1)$ & * \\
\hline
\end{tabular}

Mean $( \pm$ SE) scores and $95 \%$ confidence intervals of the laboratory test data. A significant $(P<.05)$ treatment effect is indicated by *; NS $=$ not significant. 


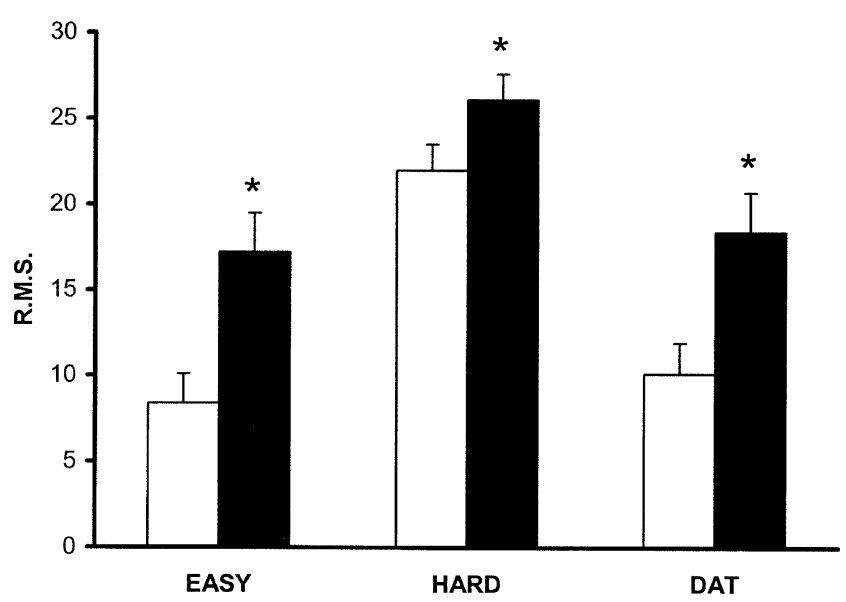

Figure 3. Motor control. Mean (+SE) RMS in the easy and hard condition of the tracking test and tracking in the divided attention test (DAT). Significant $(p<.05)$ differences from placebo are indicated by ${ }^{*} \mathbf{\square}=$ alprazolam; $\square=$ placebo.

scanning test $(\mathrm{r}=.51, p<.02)$. However, easy tracking, reaction time in the divided attention test, and percentage errors in the divided attention test and Sternberg memory scanning test did not correlate significantly with SDLP. Subjective assessments show similar inconsistency. Subjective driving quality and mental effort scores do not correlate significantly with SDLP, whereas significant correlations are found between SDLP and assessments of mental activation $(\mathrm{r}=-.52, p<$ $.02)$ and alertness $(\mathrm{r}=-.46, p<.04)$.

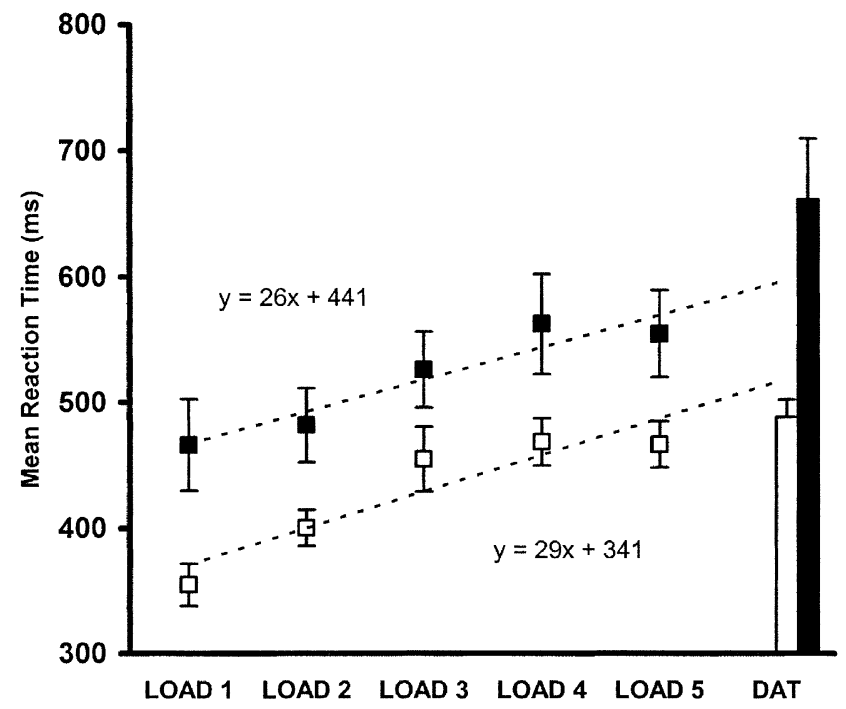

A

\section{DISCUSSION}

The present results reveal supportive evidence for the two hypotheses of this study. The findings indicate detrimental effects on actual driving, laboratory tracking, memory functioning and divided attention after acute treatment with alprazolam. Regarding driving, excessive side-to-side motions within the right traffic lane resulted in increased excursions out of lane. Moreover, six out of twenty subjects were unable to complete their driving test. The driving instructor had to intervene and correct their driving several times, in order to prevent serious collisions from happening. Although these six subjects invested considerable effort to drive carefully and maintain alert, all of them fell asleep while driving within the first half of their driving test. The objective driving impairment after alprazolam was confirmed by subjective assessments, showing poorer driving quality, decreased alertness, decreased mental activation and increased mental effort during driving.

To date, the effects of various benzodiazepines on driving performance were determined employing onthe-road driving tests during normal traffic. In general, these studies showed a dose-dependent impairment of driving performance, comparable to impairment found after ethanol doses up to $0.10 \%$ (Van Laar and Volkerts 1998).

In the present study, alprazolam caused an increment in SDLP of approximately $9 \mathrm{~cm}$, which is comparable to driving impairment with a blood alcohol concentration of $0.15 \%$ (Louwerens et al. 1986). According to an epidemiological study of Borkenstein et al. (1964)

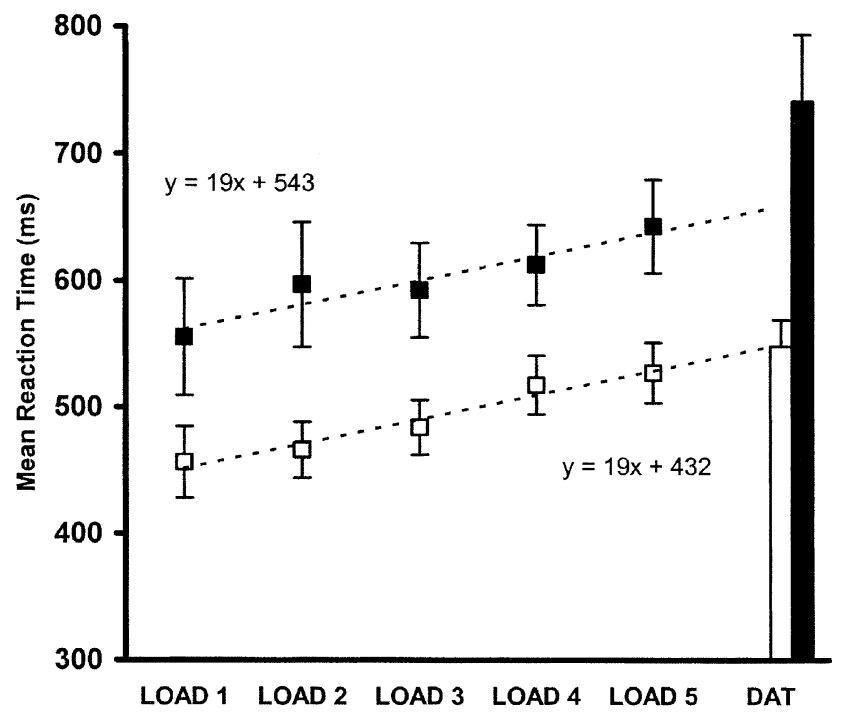

Figure 4. Memory functioning. Mean $(+\mathrm{SE})$ reaction time for each memory load in the Sternberg Memory Scanning Test and the Divided Attention Test (DAT) for presented digits (A) and not presented digits (B). $\mathbf{\square}=$ alprazolam; $\square=$ placebo. 
in which blood alcohol concentrations were correlated with traffic accident risk, a blood alcohol concentration above $0.15 \%$ corresponds at least to a 25 -fold increased traffic accident risk.

In accordance with the gross decrement in driving performance, motor control (i.e. tracking ability) was significantly affected under laboratory conditions as well. These findings are in line with results from other studies (Ellinwood et al. 1985, 1987; Linnoila et al. 1990; Nikaido et al. 1990; Ellinwood et al. 1993; Vermeeren et al. 1995; Kroboth et al. 1998) showing significantly impaired tracking ability after alprazolam.

Reaction time after alprazolam was significantly increased in both memory scanning tests. Moreover, alprazolam significantly increased errors in the divided attention test. This finding was not observed in the Sternberg memory scanning test, in which processing demands are low, relative to the divided attention test. Finally, these findings are in line with those reported by other investigators (Blom et al. 1990; Suzuki et al. 1995).

On first sight it is perhaps surprising that the majority of laboratory test parameters do not correlate significantly with objective driving performance (SDLP). Moreover, those correlations that reached significance are only of moderate strength $(\mathrm{r} \approx .50)$. Although performance in the hard version of the tracking test highly correlates with SDLP $(r=.90)$, this is not the case for easy tracking and tracking in the divided attention test. Thus, actual driving ability cannot be adequately predicted from the results obtained in our laboratory test battery, and this observation stresses the importance of conducting on-the-road driving tests instead of making judgments concerning driving ability based solely upon psychometric test results.

The clinical relevance of our results is limited by the fact that we administered a single dose of alprazolam to healthy young volunteers, while in practice alprazolam is used chronically by patients suffering from anxiety or panic attacks. Moreover, even without pharmacological treatment these patients show significantly impaired performance, relative to control subjects (e.g., Dratcu and Bond 1998), and this 'baseline impairment' is additive to the treatment-induced effects. Further, it is of concern that these patients were unable to judge their performance quality accurately, since this presumably leads to engagement in potentially dangerous activities such as driving. Unfortunately, the number of behavioral studies with patients treated with alprazolam is very limited (e.g., Curran et al. 1994). Based upon their results it is premature to draw firm conclusions regarding driving ability after chronic alprazolam use. Behavioral studies with healthy volunteers generally show a change from baseline performance on laboratory tests after chronic administration of alprazolam (e.g. Aranko et al. 1985, Seidel et al. 1985, Subhan et al. 1986, Kumar et al. 1987, Smith and Kroboth 1987, Jurado et al. 1989,
Hart et al. 1991, Pomara et al. 1998). It is however unclear whether this effect is caused by the development of tolerance to alprazolam's sedative effects, or due to learning effects. That is, improvement of test performance is often observed after repeated conductance of laboratory tests such as the DSST, and this impairment decrement is easily confused with the development of tolerance. In this context, repeated measurements of driving ability are much more appropriate, since driving is an example of skilled behavior practiced on a daily basis. Previous research conducted in our department (Van Laar et al. 1992) showed that driving ability of outpatients with generalized anxiety disorder was significantly impaired during the first three weeks of diazepam treatment ( $5 \mathrm{mg}$ t.i.d.). It can be expected that alprazolam shows similar impairing effects after chronic administration. Future research should therefore focus on the effects of chronic alprazolam use on driving ability, and its dose-response relationship, in the intended patient population.

In conclusion, on-the-road driving is seriously impaired after alprazolam, and laboratory results confirm this detrimental effect of the drug on driving ability. Therefore, general physicians are urged to warn patients on alprazolam not to drive a car or operate potentially dangerous machinery.

\section{ACKNOWLEDGMENTS}

This study was supported by Wyeth-Ayerst Research.

\section{REFERENCES}

Aranko K, Mattila MJ, Bordignon D (1985): Psychomotor effects of alprazolam and diazepam during acute and subacute treatment, and during the follow-up phase. Acta Pharmacol Toxicol 56:364-372

Barbone F, McMahon AD, Davey PG, Morris AD, Reid IC, McDevitt DG, MacDonald TM (1998): Association of road-traffic accidents with benzodiazepine use. Lancet 352:1331-1336

Beringer J (1992): ERTS: Experimentelles Run Time System (3.17). Darmstadt, Germany, Institut für Psychologie

Block RI, Berchou R (1984): Alprazolam and lorazepam effects on memory acquisition and retrieval processes. Pharmacol Biochem Behav 20:233-241

Blom MW, Bartel PR, De Sommers K, Van der Meyden CH, Becker PJ (1990): The effects of alprazolam, quazepam and diazepam on saccadic eye movements, parameters of psychomotor function and the EEG. Fundam Clin Pharmacol 4:653-661

Bond A, Silveira JC, Lader M (1991): Effects of single doses of alprazolam and alcohol alone and in combination on psychological performance. Hum Psychopharmacol 6:219-228 
Borkenstein RF, Crowther RP, Shumate RP, Ziel HB, Zylman $R$ (1964): The role of the drinking driver in traffic accidents. Bloomington, IN, Dept. of Police Administration, Indiana University

Casacalenda N, Boulenger J (1998): Pharmacologic treatments effective in both generalized anxiety disorder and major depressive disorder: clinical and theoretical implications. Can J Psychiatry 43:722-730

Curran HV, Bond A, O'Sullivan G, Bruce M, Marks I, Lelliot P, Shine P, Lader M (1994): Memory functions, alprazolam and exposure therapy: a controlled longitudinal study of agoraphobia with panic disorder. Psychol Med 24:969-976

Danjou P, Warot D, Hergueta T, Lacomblez L, Bouhours P, Puech AJ (1992): Comparative study of the psychomotor and antistress effects of ritanserin, alprazolam and diazepam in healthy subjects: some trait anxiety-independent responses. Int Clin Psychopharmacol 7:73-79

Dratcu L, Bond A (1998): Panic patients in the non-panic state: physiological and cognitive dysfunction. Eur Psychiatry 13:18-25

Ellinwood EH, Heatherly DG, Nikaido AM, Bjornsson TD, Kilts C (1985): Comparative pharmacokinetics and pharmacodynamics of lorazepam, alprazolam and diazepam. Psychopharmacology (Berl) 86:392-399

Ellinwood EH, Nikaido AM, Heatherly DG, Bjornsson TD (1987): Benzodiazepine pharmacodynamics: evidence for biophase rate limiting mechanisms. Psychopharmacology (Berl) 91:168-174

Ellinwood EH, Nikaido AM, Gupta SK, Heatherly DG, Hege $S$ (1993): Comparison of the relationship between structure and CNS effects for lorazepam, clonazepam and alprazolam. J Psychopharmacol 7:24-32

Hart RP, Colenda CC, Hamer RM (1991): Effects of buspirone and alprazolam on the cognitive performance of normal elderly subjects. Am J Psychiatry 148:73-77

Hemmelgarn B, Suissa S, Huang A, Boivin J-F, Pinard G (1997): Benzodiazepine use and the risk of motor vehicle crash in the elderly. JAMA 278:27-31

Hindmarch I (1983): Measuring the side-effects of psychoactive drugs: a pharmacodynamic profile of alprazolam. Alcohol Alcohol 18:361-367

Jonas JM, Cohon MS (1993): A comparison of the safety and efficacy of alprazolam versus other agents in the treatment of anxiety, panic, and depression: a review of the literature. J Clin Psychiatry 54(Suppl.):25-45

Julien RM (1998): Central nervous system depressants: alcohol and the inhalants of abuse. In Julien RM (ed), A Primer of Drug Action: A Concise, Nontechnical Guide to the Actions, Uses and Side Effects of Psychoactive Drugs. New York, W.H.Freedman and Company, pp 64-92

Jurado JL, Fernández-Mas R, Fernández-Guardiola A (1989): Effects of 1 week administration of two benzodiazepines on the sleep and early daytime performance of normal subjects. Psychopharmacology (Berl) 99:91-93

Kožená L, Frantik E, Horváth M (1995): Vigilance impairment after a single dose of benzodiazepines. Psychopharmacology (Berl) 119:39-46

Kroboth PD, Folan MM, Bauer KS, Tullock W, Wright CE, Sweeney JA (1998): Do alprazolam-induced changes in saccadic eye movement and psychomotor function follow the same time course? J Clin Pharmacol 38:337-346

Kumar R, Mac DS, Gabrielli WF, Goodwin DW (1987): Anxiolytics and memory: a comparison of lorazepam and alprazolam. J Clin Psychiatry 48:158-160

Linnoila M, Stapleton JM, Lister R, Moss H, Lane E, Granger A, Eckhardt MJ (1990): Effects of single doses of alprazolam and diazepam, alone and in combination with ethanol, on psychomotor and cognitive performance and on autonomic nervous system reactivity in healthy volunteers. Eur J Clin Pharmacol 39:21-28

Louwerens JW, Gloerich ABM, De Vries G, Brookhuis KA, O'Hanlon JF (1986): The relationship between drivers' blood alcohol concentration (BAC) and actual driving performance during high speed travel. Proceedings of the 10th International Conference on Alcohol, Drugs and Traffic Safety, Amsterdam

Mendelson WB (1996): The use of sedative/hypnotic medication and its correlation with falling down in the hospital. Sleep 19:698-701

Neutel CI (1995): Risk of a traffic accident injury after a prescription for a benzodiazepine. Ann Epidemiol 5:239-244

Nikaido AM, Ellinwood EH, Heatherly DG, Gupta SK (1990): Age-related increase in CNS sensitivity to benzodiazepines as assessed by task difficulty. Psychopharmacology (Berl) 100:90-97

Petty F, Trivedi MH, Fulton M, Rush AJ (1995): Benzodiazepines as antidepressants: does GABA play a role in depression? Biol Psychiatry 38:578-591

Pomara N, Tun H, DaSilva D, Hernando R, Deptula D, Greenblatt DJ (1998): The acute and chronic performance effects of alprazolam and lorazepam in the elderly: relationship to duration of treatment and selfrated sedation. Psychopharmacol Bull 34:139-153

Ray WA, Griffin MR, Schaffner W, Bauch DK, Melton LJ (1987): Psychotropic drug use and the risk of hip fracture. N Eng J Med 316:363-369

Ray WA, Griffin MR, Downey W (1989): Benzodiazepines of long and short elimination half-life and the risk of hip fracture. JAMA 262:3303-3307

RxList (2000): Top 200 prescriptions for 2000 by number of US prescriptions dispensed. Internet: www.rxlist.com/ top200.htm

Rudolph U, Crestani F, Möhler H (2001): GABA A receptor subtypes: dissecting their pharmacological functions. Trends Pharmacol Sci 22:188-194

Saletu B, Grünberger J, Linzmayer L, Semlitsch HV, Anderer P, Chwatal K (1994): Pharmacokinetic and -dynamic studies with a new anxiolytic, suriclone, utilizing EEG mapping and psychometry. Br J Clin Pharmacol 37:145156

Seidel WF, Cohen L, Wilson L, Dement WC (1985): Effects of alprazolam and diazepam on the daytime sleepiness of non-anxious subjects. Psychopharmacology (Berl) 87: 194-197

Smith RB, Kroboth PD (1987): Influence of dosing regimen on alprazolam and metabolite serum concentrations and tolerance to sedative and psychomotor effects. Psychopharmacology (Berl) 93:105-112

Subhan Z, Harrison Ch, Hindmarch I (1986): Alprazolam 
and lorazepam. Single and multiple-dose effects on psychomotor skills and sleep. Eur J Clin Pharmacol 29:709712

O'Sullivan GH, Noshirvani H, Başoğlu M, Marks IM, Swinson R, Kuch K, Kirby M (1994): Safety and sideeffects of alprazolam. Controlled study in agoraphobia with panic disorder. Br J Psychiatry 165: 79-86

Suzuki M, Uchiumi M, Murasaki M (1995): A comparative study of the psychological effects of DN-2327, a partial benzodiazepine agonist, and alprazolam. Psychopharmacology (Berl) 121:442-450

Van Laar MW, Volkerts ER, Willigenburg APP (1992): Therapeutic effects and effects on actual driving performance of chronically administered buspirone and diazepam in anxious outpatients. J Clin Psychopharmacol 12:86-95
Van Laar MW, Volkerts ER (1998): Driving and benzodiazepine use. Evidence that they do not mix. CNS Drugs 10:383-396

Vermeeren A, Jackson JL, Muntjewerff ND, Quint PJ, Harrison EM, O'Hanlon JF (1995): Comparison of acute alprazolam $(0.25,0.50$ and $1.0 \mathrm{mg})$ effects versus those of lorazepam $2 \mathrm{mg}$ and placebo on memory in healthy volunteers using laboratory and telephone tests. Psychopharmacology (Berl) 118:1-9

Volkerts ER, Van Laar MW, Van Willigenburg APP, Plomp TA, Maes RAA (1992): A comparative study of on-theroad and simulated driving performance after nocturnal treatment with lormetazepam $1 \mathrm{mg}$ and oxazepam $50 \mathrm{mg}$. Hum Psychopharmacol 7:297-309

Weinberger DR (2001): Anxiety at the frontier of molecular medicine. N Eng J Med 344:1247-1249 